\title{
CONTRIBUIÇÃO AO CONHECIMENTO DO SISTEMA RADICULAR DA PUPUNHEIRA (Bactris gasipaes KUNTH, PALMAE). II. SOLO LATOSSOLO AMARELO, TEXTURA ARGILOSA. ${ }^{1}$
}

\author{
Sidney A. do N. FERREIRA ${ }^{2}$, Charles R. CLEMENT ${ }^{2}$, Guido RANZANI ${ }^{3}$, Suely \\ de S. COSTA ${ }^{2}$
}

RESUMO - A distribuição da biomassa e da área absorvente do sistema radicular da pupunheira (Bactris gasipaes) foram estudadas num latossolo amarelo, textura argilosa, perto de Manaus, Amazonas, Brasil. Aproximadamente $80 \%$ da biomassa se encontrava no horizonte Ap, da qual $90 \%$ se encontrava dentro da área de projeção da copa. A biomassa total estimada pesou $72 \mathrm{~kg}$, excluindo-se a massa logo abaixo do estipe. A área superficial das raizes aumentou significativamente conforme se afastava do estipe, devido a proporção cada vez maior de raízes terciárias e quartenárias, embora sua abundância por $\mathrm{m}^{3}$ diminuiu de forma similar à biomassa. A área superficial total estimada chegou a $545 \mathrm{~m}^{2}$, da qual se supõe que $50 \%$ é ativa na absorção de nutrientes. Supõe-se ainda que existam raízes absorventes até 8-9 $\mathrm{m}$ do estipe das plantas. Recomenda-se que a adubação seja feita dentro e logo fora da projeção da copa.

Palavras-chave: Pupunha, Bactris gasipaes, sistema radicular, biomassa, área das raizes absorvente.

Contribution to the Knowledge of Root System of the Pejibaye (Bactris gasipaes Kunth, Palmae). II. Yellow Oxisol, Clay Texture.

ABSTRACT - The distribution of the pejibaye's (Bactris gasipaes) root biomass and absorbtive area was studied in a clay textured, yellow Oxisol, near Manaus, Amazonas, Brazil. Approximately $80 \%$ of the biomass was found in the Ap horizon and $90 \%$ of this within the crown projection area. Total biomass was estimated at $72 \mathrm{~kg}$, without, however, including the very large mass immediately below the stem. The root surface area increased significantly as distance from the stem increased, due to the increase in the proportion of third and fourth order roots, although its abundance per $\mathrm{m}^{3}$ diminished like that of the biomass. The total root surface area was estimated at $545 \mathrm{~m}^{2}$, of which $50 \%$ is probably active in nutrient absorbtion. The observed distribution suggested that there are absorbtive roots at least $8-9 \mathrm{~m}$ from the stem. Fertilizer placement should be within and just outside of the crown projection area.

Key-words: Pejibaye, Bactris gasipaes, root system, biomass, root absorbtive area.

\section{INTRODUÇÃO}

O presente trabalho é continuação do estudo sobre o sistema radicular da pupunheira (Bactris gasipaes Kunth) iniciado por FERREIRA et al. (1980). As árvores avaliadas neste estudo foram de idade similares as do primeiro, porém foram localizadas em solo e sistema de manejo diferentes. Estas condições influenciaram o crescimento das plantas, especialmente em seus sistemas radiculares.

FERREIRA et al. (1980) apresentaram a distribuição física das raízes (peso seco) dentro do perfil de solo, porém esta não revela a área real absorvente do sistema radicular de

Financiado pelo convênio POLAMAZONIA/CNPq-INPA.

2 Coordenadoria de Pesquisas em Ciências Agronômicas, Instituto Nacional de Pesquisas da Amazônia - INPA, Cx. Postal 478, 6901I Manaus, AM, Brasil.

3 Rua Prudente de Morais, 1941, Apto. 83, 13416-720 Piracicaba, SP, Brasil 
maneira satisfatória (SCHUURMAN \& GOEDEWAAGEN, 1965). Melhores aproximações são obtidas com informações sobre a área superficial das raízes (ibid), especialmente quando as raízes são classificadas de acordo com o seu diâmetro (TAILLIEZ, 1971), pois é conhecido que diferentes classes de raízes possuem diferentes funções (PANDALAI, 1960; PURVIS, 1956).

Em côco (Cocos nucifera L.) e dendê (Elaeis guineensis Jacq.) as raízes primárias são utilizadas principalmente para o suporte físico das plantas e o transporte de água e nutrientes (PANDALAI, 1960; PURVIS, 1956). As extremidades dessas raízes em crescimento também são ativas na absorção de água e nutrientes (RUER, 1967b). As raízes secundárias são usadas principalmente no transporte, também com suas extremidades ativas na absorção. As raízes terciárias e quaternárias são responsáveis pela maior parte da absorção (PANDALAI, 1960; RUER, 1967b) e na pupunheira são essas que são infectadas por micorrizas (JANOS, 1977).

O conhecimento da distribuição das diversas classes de raízes, especialmente as terciárias e quaternárias, permitirá um manejo mais racional da planta em sistemas agrícolas.

\section{MATERIAL E MÉTODOS}

O estudo foi realizado no terreno do Sr. Thales Loureiro, km 21 da AM010 (estrada Manaus-Itacoatiara), município de Manaus, Amazonas, Brasil, durante o mês de julho de 1981. A Tabela 1 apresenta a descrição morfológica do perfil do solo e
Tabela 2 os resultados analíticos. O clima de Manaus é "Afi", no sistema de Köppen (RIBEIRO, 1976), com pluviosidade média anual de 2.478 $\mathrm{mm}$, temperatura média anual de $25,6^{\circ} \mathrm{C}$, e época de estiagem de Junho a Setembro.

Sete pupunheiras (raça 'microcarpa' Pará (MORA URPI \& CLEMENT, 1988)) foram escolhidas sistematicamente para evitar ao máximo a superposição dos sistemas radiculares. As árvores estavam com 17 anos de idade, altura de $14,4 \pm 2,1$ $\mathrm{m}$, e diâmetro da copa de 4,6 $\pm 0,5 \mathrm{~m}$ (médias \pm desvio padrão). As plantas se encontravam em um campo de pastagem (com bovinos e equinos), sendo adubadas ocasionalmente por excremento animal. Devido a que esses animais comerem os perfilhos e as raízes adventícias das plantas, o desenvolvimento de touceiras e de novas raízes primárias, respectivamente, foram impedidos.

A coleta das amostras seguiu a metodologia de FERREIRA et al. (1980). As raízes frescas e limpas foram classificadas em primárias, secundárias e terciárias + quaternárias, pesadas e seus diâmetros medidos. As raízes terciárias e quaternárias foram agrupadas não só por apresentarem funções similares mas também por serem mais finas e facilmente fragmentáveis. O êrro em reunir esses dois tamanhos de raízes é considerado a ser relativamente pequeno (SCHUURMAN \& GUEDEWAAGEN, 1965). Posteriormente, as raízes foram secas em estufa a $70^{\circ} \mathrm{C}$ até peso contante. Baseando-se no volume total do solo utilizado pela planta 
Tabela 1. Descrição morfológica do perfil do solo no $\mathrm{km} 21$ da AM-010, onde se encontra as 7 pupunheiras estudadas.

Classificação: Latossolo amarelo álico, $\mathrm{A}$ fraco, textura muito argilosa.

Declividade: $2-3 \%$

Relevo: Plano a suave ondulado; topo de extenso platô.

Material de origem: Sedimentos terciários, argilosos, provavelmente da Formação Barreiras.

Drenagem: Boa.

Erosão: Ausente.

Morfologia:

-A 0-12 cm; matriz pardo amarelado escuro (10 YR 5/4 úmido, 10 YR 6/3 amassado), com pequenas manchas amarelo (10 YR 7/6), comuns, pouco nitidas; argila arenosa; granular pequena a média, moderado; duro friável, plástico, ligeiramente pegajoso; carvões pequenos, comuns; raízes muito finas abundantes; galerias biológicas pequenas, comuns; limite suave, claro.

-A 12-27 cm; matriz amarelo (10 YR 7/6 umido) com marchetamento pequeno, pardo amarelado (10 YR 5/4), comun, pouco nítido; argila; blocos subangulares médios, moderado; muito duro, friável, plástico, pegajoso; carvões pequenos comuns; raízes muito finas, pouco; galerias biológicas pequenas, pouco; limite suave, gradual.

-B $27-50 \mathrm{~cm}$; amarelo (10 YR 7/6 umido); argila; maciço que se rompe em blocos sub-angulares grandes, moderado a fraco; duro, friável, muito plástico, muito pegajoso; carvões pequenos a médios comuns; raízes muito finas, pouco; limite suave, difuso.-B $50-87 \mathrm{~cm}$; amarelo pardacento (10 YR 6/6 umido); argila; maciço; duro, friável, muito plástico, muito pegajoso; carvões muito pequenos, pouco; raízes muito finas, pouco; limite suave, difuso.

-B 27 7-132 cm; amarelo pardacento (10 YR 6/6 umido); argila; maciço; duro, friável, muito plástico, muito pegajoso; limite suave, difuso.

-By $/$ C 132-200 cm; matriz amarelo (10 YR umido) com grandes áreas mais amarelas (10 YR 8/6 umido), nitidas; argila; maciço; macio, friável, plástico, pegajoso.

Tabela 2. Resultados analíticos do perfil do solo em que se encontram as pupunheiras estudadas.

O solo é um Latossolo Amarelo, álico, textura argilosa (veja Tab. 1).

\begin{tabular}{|c|c|c|c|c|c|c|c|}
\hline $\begin{array}{l}\text { HORIZONTE: } \\
\text { Análise }\end{array}$ & & Ap & $A_{3}$ & $\mathrm{~B}_{1}$ & $\mathrm{~B}_{21}$ & $\mathrm{~B}_{33}$ & $\mathrm{~B}_{3} / \mathrm{C}$ \\
\hline $\mathrm{pH} \mathrm{em} \mathrm{H} \mathrm{H}_{2} \mathrm{O}$ & & 4,1 & 4,3 & 4,4 & 4,3 & 4,6 & 5,0 \\
\hline em KCIN & & 3,8 & 3,9 & 3,9 & 4,0 & 4,3 & 4,4 \\
\hline Textura: & areia & 52 & 39 & 38 & 37 & 37 & 37 \\
\hline \multirow[t]{2}{*}{$(\mathrm{em} \%)$} & silte & 1 & 5 & 4 & 3 & 8 & 7 \\
\hline & argila & 47 & 56 & 58 & 60 & 55 & 56 \\
\hline \multirow{6}{*}{$\begin{array}{l}\text { Cations trocáveis } \\
\left(\text { meq. } 100 \mathrm{~g}^{-1}\right)\end{array}$} & & & & & & & \\
\hline & $\mathrm{Na}$ & 0,04 & 0,02 & 0,02 & 0,02 & 0,02 & 0,01 \\
\hline & K & 0,08 & 0,03 & 0,01 & 0,01 & 0,01 & 0,01 \\
\hline & $\mathrm{Mg}$ & 0,53 & 0,42 & 0,37 & 0,40 & 0,46 & 0,48 \\
\hline & $\mathrm{Ca}$ & 0,01 & 0,01 & 0,03 & 0,01 & 0,01 & 0,01 \\
\hline & PO4 & 0,08 & 0,03 & 0,01 & 0,01 & 0,08 & 0,08 \\
\hline \multicolumn{8}{|l|}{ Alumínio trocável } \\
\hline (meq. $100 \mathrm{~g}^{-1}$ ) & & 1,76 & 1,31 & 1,23 & 0,96 & 0,33 & 0,22 \\
\hline \multicolumn{8}{|l|}{ Hidrogênio trocável } \\
\hline (meq. $100 \mathrm{~g}^{-1}$ ) & & 6,00 & 3,92 & 3,12 & 2,24 & 1,76 & 1,44 \\
\hline Carbono orgânico (\%) & & 0,34 & 1,45 & 0,52 & 0,23 & 0,11 & 0,05 \\
\hline Nitrogênio (\%) & & 0,25 & 0,20 & 0,14 & 0,13 & 0,14 & 0,10 \\
\hline Relação C/N & & 1,4 & 7,2 & 3,7 & 1,8 & 0,8 & 0,5 \\
\hline
\end{tabular}


estimou-se a biomassa total das raízes. Para comparação, estimou-se a biomassa das árvores estudadas por FERREIRA et al. (1980) também.

A análise preliminar permitiu a seleção da árvore que mais se aproximou da média geral para estimar a área superficial. Dado a quantidade e a forma irregular das raízes, estimouse os comprimentos das raízes frescas da árvore escolhida em lugar de medílas diretamente (MARSH, 1971). Com as estimativas de comprimento (c) e as classificações de diâmetro (d), estimou-se a área superficial (a) das raízes desta árvore $\left(a=\Pi^{*} d^{*} c\right)$. Estimou-se a área superficial total das raízes no volume total do solo usado pela planta.

Utilizou-se a regressão curvilinear (SOKAL \& ROLF, 1981) para analisar as tendências evidentes nos dados, tanto das médias obtidas como da árvore escolhida para representálas. Inicialmente se examinou as tendências ao longo da linha de coleta das amostras, que resultou numa regressão curvilinear simples, com a distância ou profundidade transformada em $1 / \mathrm{X}$. Posteriormente se examinou as tendências volumétricas, que resultou numa regressão similar na profundidade, $\mathrm{e}$ numa regressão múltipla $\left(\mathrm{X}_{\mathrm{i}}\right.$ e $\left.\mathrm{X}_{\mathrm{i}}^{2}\right)$ na distância.

\section{RESULTADOS E DISCUSSÃO}

Aproximadamente $80 \%$ da biomassa radicular foi encontrada nos primeiros $20 \mathrm{~cm}$ do perfí, que corresponde ao horizonte Ap e uma parte da $\mathrm{A}_{3}$ (Fig. 1). A regressão, $Y_{i}=-11,6+1337,96 * 1 /$ $\mathrm{X}$, explica $86 \%$ da variação na distribuição da biomassa radicular em profundidade devido a grande quantidade de raízes na primeira camada. Em comparação, num latossolo amarelo, textura média, FERREIRA et al. (1980) encontraram apenas $58 \%$ da biomassa radicular amostrada nesta camada, enquanto, num solo aluvial do litoral Pacífico da Colombia, com lençol freático a $1,2 \mathrm{~m}$ de profundidade, apenas $52 \%$ foi encontrada (RIVERA \& TRUJILLO, 1981). Supõe-se que esta concentração de raízes seja devida à maior densidade do solo nos horizontes inferiores.

A distribuição lateral da biomassa radicular amostrada nesta primeira camada é também concentrada próximo da árvore (Figura 2), principalmente dentro da projeção da copa (1,5 m raio). Quase 93\% da biomassa amostrada nesta camada se encontra nesta área, que corresponde a $74 \%$ da biomassa total. Embora a maioria da biomassa se localize perto do estipe, a regressão, $Y_{i}=-9,6+$ $3661,55 * 1 / X_{i}$, explica $96 \%$ da variação na distribuição em distância. Em comparação, FERREIRA et al. (1980) encontraram 48\% nesta posição e RIVERA \& TRUJILLO (1981) apenas $27 \%$. Supõe-se que esta concentração seja devido ao pisoteio pelo gado nas áreas mais distantes do estipe.

Adicionalmente, $90 \%$ do total da biomassa radicular amostrada (até uma profundidade de $2 \mathrm{~m}$ ) foi encontrada dentro da projeção da copa. Esta proporção é comparável aos $82 \%$ num latossolo amarelo, textura média (FERREIRA et al., 1980), embora é muito maior que os $41 \%$ num solo aluvial (RIVERA \& TRUJILLO, 


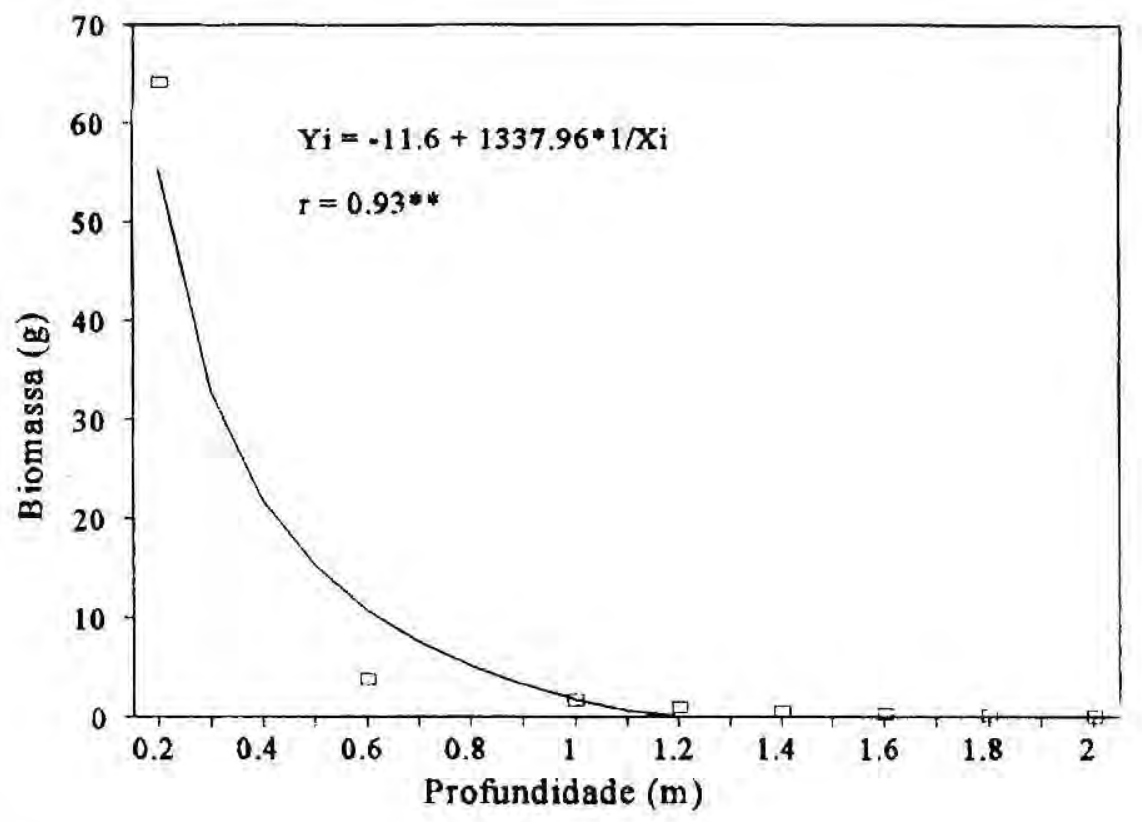

Figura 1. Distribuição em profundidade da biomassa radicular amostrada de pupunheiras (média de 7 plantas) crescendo num latossolo amarelo, textura argilosa.

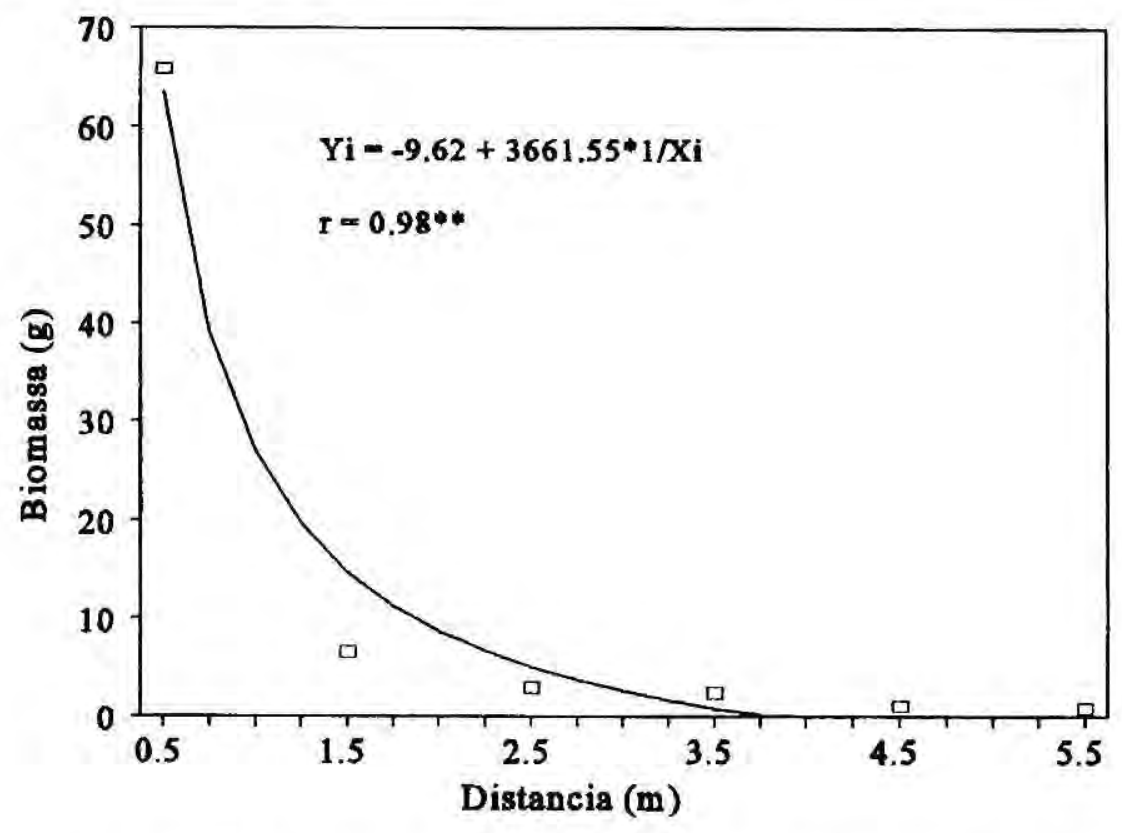

Figura 2. Distribuição em distância do estipe da biomassa radicular amostrada de pupunheiras (média de 7 plantas) crescendo num latossolo amarelo, textura argilosa. 
1981). Este parece ser devido a uma maior concentração de raízes primárias que fornecem suporte físico para a planta. Fato similar ocorre no dendê (HARTLEY, 1977) e no côco (CHILD, 1974).

As sete árvores apresentaram uma biomassa radicular média estimada de $72,6 \mathrm{~kg}$ dentro do volume estudado, excluindo-se a massa radicular imediatamente abaixo do estipe. VANDERMEER (1977) demonstrou que esta massa radicular, não calculada nem amostrada aqui, é bastante densa. Portanto, a estimativa aqui apresentada é menor que a biomassa radicular real. Com as mesmas limitações de amostragem, FERREIRA et al. (1980) encontraram uma média de $164,3 \mathrm{~kg}$ de biomassa radicular total (estimada aqui) num latossolo amarelo, textura média, com árvores $(n=7)$ apresentando as seguintes características: altura máxima $=9,1 \pm 1,4 \mathrm{~m}$; diâmetro da copa $=4,8 \pm 0,8 \mathrm{~m}$; estipes/touceira $=$ $5,6 \pm 2,8)$. A biomassa aérea dessas plantas parece ser bem maior que a das plantas aqui estudadas, de forma que a grande diferença na biomassa radicular estimada nos dois estudos faz sentido. Adicionalmente, o latossolo amarelo, textura média, parece ser um ambiente edafológico mais favorável para a pupunheira, devido a menor densidade do solo nos horizontes profundos.

Os diâmetros médios das três classes de raízes usadas neste estudo (Tab. 3) são um pouco menores que os encontrados por RIVERA \& TRUJILLO (1981). Não existe bastante conhecimento sobre o sistema radicular da pupunha para saber se estas diferenças são genéticas ou ambientais. As pupunheiras deste estudo são da raça 'microcarpa' Pará, enquanto as de RIVERA \& TRUJILLO (1981) são de uma raça 'mesocarpa' do litoral Pacífico da Colombia. O solo estudado é um latossolo argiloso, enquanto o da Colombia é solo aluvial e textura arenosa a média. A preciptação pluviométrica de Manaus também contrasta com os $6.000 \mathrm{~mm}$ de chuva, sem estiagem, do litoral colombiano. As distribuições da área superficial radicular amostrada, tanto em profundidade como em distância do estipe, foram similares as distribuições da biomassa radicular. Apenas as regressões são apresentadas, subdividas pelas classes de diâmetro (Tab. 4). Conforme mais se afasta do estipe, maior é a proporção de raízes das classes terciárias e quartenárias. As regressões desta classe não chegam a um zero teórico até quando estas raízes atingem uma profundidade ou distância muito além da observada.

As distribuições da área superficial radicular total no volume de solo estudado se comportaram de forma distinta. Em profundidade (Fig. 3) o comportamento foi similar ao das amostras e da biomassa total. Os modelos das regressões que explicam este comportamento são também similares, exceto para as raízes terciárias e quartenárias (Tab. 5). Embora as raízes primárias não foram representadas nas amostras profundas e a curva da regressão vai ao zero quando atinge um metro de profundidade, esta classe de raízes deveria estar presente, 
Tabela 3. Diâmetro médio (mm) das classes de raízes de pupunha.

\begin{tabular}{lccccc}
\hline \multirow{2}{*}{ FONTE } & \multicolumn{5}{c}{ CLASSES } \\
Rivera \& Trujillo (1981) & $1^{\mathrm{a}}$ & $2^{\mathrm{a}}$ & $3^{\mathrm{a}}$ & $4^{\mathrm{a}}$ \\
O presente estudo & 5.7 & 3.5 & 1.4 & & 0.7 \\
\hline
\end{tabular}

Tabela 4. Regressões com transformações inversas nas distribuições da área superficial radicular amostrada $(n=1)$ em profundidade (A) e em distância do estipe (B), subdivididas por classe de diâmetro.

\begin{tabular}{lll}
\hline CLASSE & \multicolumn{1}{c}{ REGRESSÃO } & $R 2$ \\
\hline A. & $Y_{i}=-169,6+31.509,5^{\star} 1 / X_{i}$ & 0.98 \\
Todas & $Y_{i}=-213,3+17.362,7^{*} 1 / X_{i}$ & 0.96 \\
$1^{\text {a }}$ & $Y_{i}=-63,0+8.888,4^{*} 1 / X_{i}$ & 0.99 \\
$2^{\text {a }}$ & $Y_{i}=12,9+7.932,6^{*} 1 / X_{i}$ & 0.88 \\
$3^{\text {a }}$ & & \\
B. & $Y_{i}=-49,6+85.537,2^{\star} 1 / X_{i}$ & 0.99 \\
Todas & $Y_{i}=-123,8+42.738,5^{\star} 1 / X_{i}$ & 0.98 \\
$1^{\text {a }}$ & $Y_{i}=-55,5+27.558,5^{*} 1 / X_{i}$ & 0.99 \\
$2^{\text {a }}$ & $Y_{i}=116,5+16.097,0^{\star} 1 / X_{i}$ & 0.91 \\
$3^{\text {a }}$ &
\end{tabular}

Tabela 5. Regressões com transformações inversas nas distribuições da área superficial radicular total estimada $(n=1)$ em profundidade $(A)$ e em distância do estipe (B), subdivididas por classe de diâmetro.

\begin{tabular}{|c|c|c|}
\hline CLASSE & REGRESSÃO & $\mathrm{R} 2$ \\
\hline \multicolumn{3}{|l|}{ A. } \\
\hline Todas & $Y_{1}=-8,1+4.280^{\star} 1 / X_{1}$ & 0.93 \\
\hline $1^{\mathrm{a}}$ & $Y_{i}=-25,0+2.345^{\star} 1 / X$ & 0.95 \\
\hline $2^{\mathrm{a}}$ & $Y_{i}=-4,0+1.174^{*} 1 / X_{i}$ & 0.98 \\
\hline $3^{\mathrm{a}}$ & $Y_{i}=14,0+957^{*} 1 / X_{i}$ & 0.43 \\
\hline \multicolumn{3}{|l|}{ B. } \\
\hline Todas & $Y_{i}=79-0,15^{*} X_{1}+4,7^{*} 10^{4} * X_{i}^{2}$ & 0.92 \\
\hline $1^{\mathrm{a}}$ & $Y_{i}=38-0,15^{\star} X_{i}+1,7^{\star} 10^{4} X_{i}^{2}$ & 0.73 \\
\hline $2^{\mathrm{a}}$ & $Y_{1}=21-0,03^{*} X_{i}+4,6^{*} 10^{6} * X_{i}^{2}$ & 0.49 \\
\hline $3^{a}$ & $Y_{1}=22-9,3^{\star} 10^{3} * X_{1}+3,5^{*} 10^{4} X_{1}^{2}$ & 0.92 \\
\hline
\end{tabular}




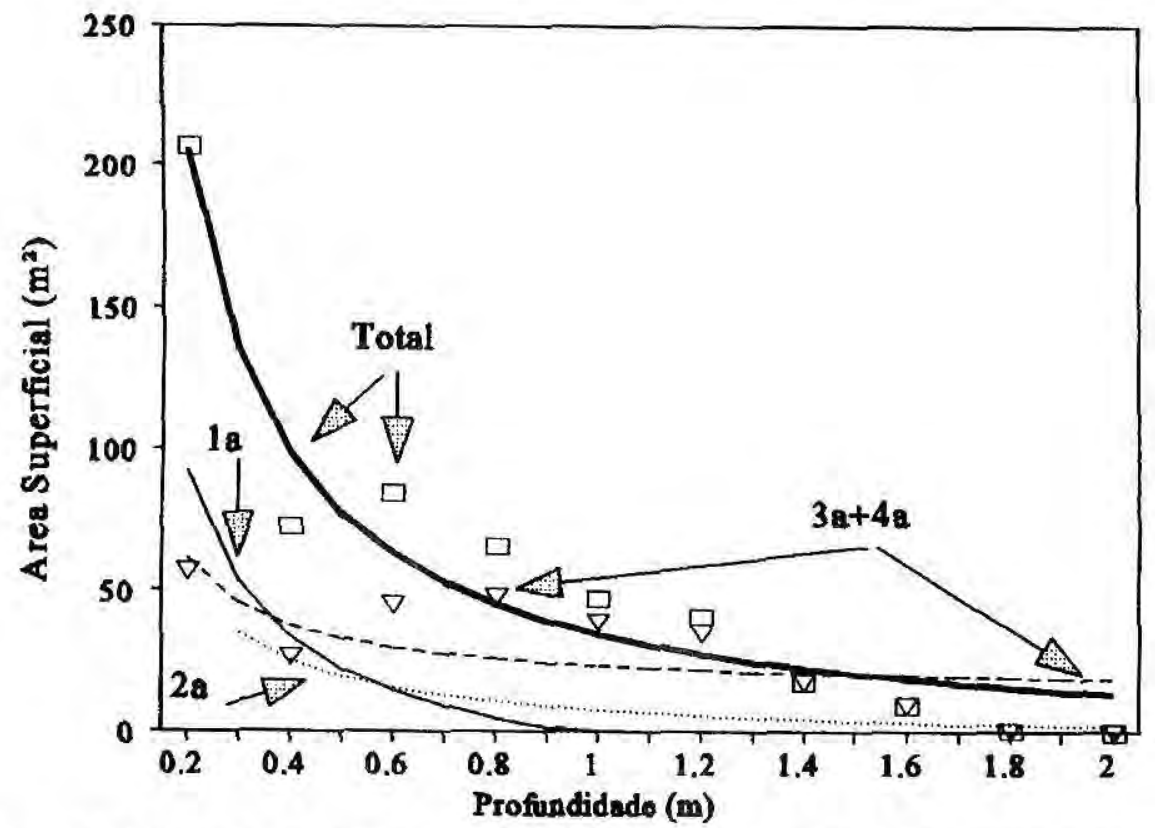

Figura 3. Distribuição em profundidade da área superficial estimada $\left(\mathrm{m}^{2}\right)$ da pupunheira média crescendo num latossolo amarelo, textura argilosa.

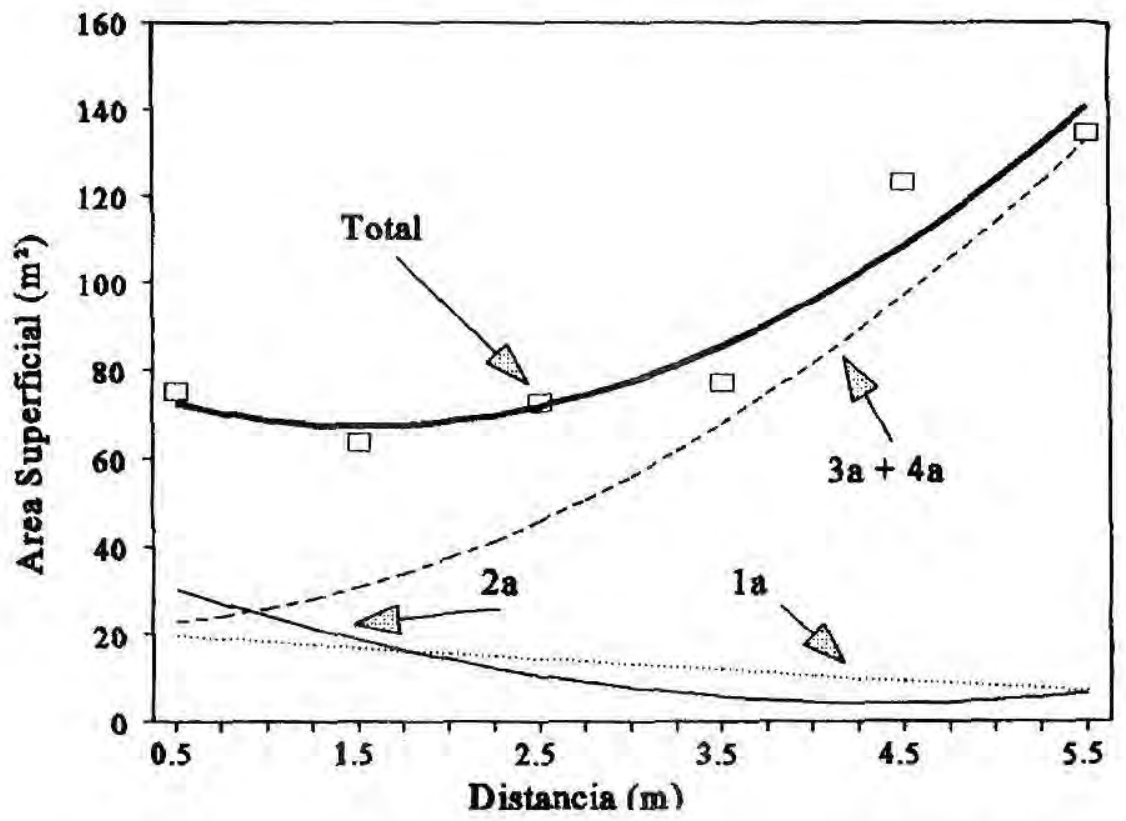

Figura 4. Distribuição em distância do estipe da área superficial estimada $\left(\mathrm{m}^{2}\right)$ da pupunheira média crescendo num latossolo amarelo, textura argilosa. 
como ocorre em dendê (RUER, 1967b) e côco (PANDALAI, 1960). Na primeira camada e próximo da planta as raízes terciárias e quartenárias são escassas, que é a razão que a regressão explica somente $43 \%$ da variação estimada. Que as raízes terciárias e quartenárias vão além da profundidade amostrada faz sentido, pois as pupunheiras tem que buscar água nas camadas mais profundas durante $o$ período de estiagem.

A distribuição em distância é distinta, pois a área superficial total aumenta conforme se afasta do estipe (Fig. 4), devido exclusivamente as raízes terciárias e quartenárias. As regressões que melhor explicam este comportamento são múltiplas, utilizando a distância e seu quadrado (Tab. 5), As raízes primárias e secundárias não se ajustam bem a este modelo, embora o conjunto das classes e as raízes terciárias e quartenárias se ajustam bem. As estimativas totais sugerem que a curva verdadeira deveria ser sigmoidal em lugar de côncava, pois de acordo com a regressão a estimativa a $5,5 \mathrm{~m}$ do estipe é menos alta do que deveria ser. No entanto, a área superficial diminui por $\mathrm{m}^{3}$ conforme se afasta do estipe, similar a curva da área superficial amostrada (Tab. 4).

Este comportamento faz sentido biológico, pois as plantas desenvolvem raízes para explorar uma maior área na busca de nutrientes. Dado a inflexão da curva além de $5,5 \mathrm{~m}$, parece razoável supor que estas plantas possuem raízes que vão além das 8-9 m. Esta situação é diferente da observada em dendê, onde a maioria da área absorvente se encontra dentro da área da projeção da copa (RUER, 1967a). No entanto, o manejo de uma plantação de dendê não pode ser comparada com o manejo destas pupunheiras, pois no primeiro caso, definida a densidade, a adubação é feita de acordo com a mesma, a fim de maximinizar a produção de frutos. Neste caso, em um campo de pastagem, a pupunha é um componente secundário que não recebe atenção específica. Além disso, se estas pupunheiras fossem adubadas, a colocação do adubo afetaria a distribuição das raízes, como acontece com o dendê (HARTLEY, 1977).

A área superficial total estimada desta árvore é de $546 \mathrm{~m}^{2}$. Se uma metade desta área for ativa na absorção de nutrientes, esta ainda é uma área enorme.

\section{CONCLUSÕES}

O sistema radicular da pupunha é mais extenso do que se estimou previamente, podendo-se supor que este alcance 8-9 $\mathrm{m}$ do estipe e a mais que $2 \mathrm{~m}$ em profundidade. Embora a maioria da biomassa radicular tenha sido encontrada dentro da área da projeção da copa, a maioria da área superfical absorvente foi encontrada fora desta área. No entanto, a maior área superficial por $\mathrm{m}^{3}$ de solo foi encontrada dentro da área de projeção da copa, de forma que a recomendação para a colocação da adubação permanece nesta área.

Baseando-se nas diferenças observadas entre as pupunheiras neste latossolo amarelo, textura argilosa, e 
as num solo similar mas de textura média, conclui-se que a consorciação de pupunha com pastoreio em alta densidade de cabeças/ha e sem maior atenção as plantas não seria aconselhável caso se procure uma alta produção de fiutos. O pisoteio do gado aparentamente prejudica o sistema radicular da pupunha nesta condição. No entanto, a pupunha parece adaptar-se bem a este solo argiloso, através de uma exploração mais intensa das camadas intermédias de profundidade.

\section{Bibliografia Citada}

CHILD, R. 1974. Coconuts, 2nd Ed. Tropical Agriculture Series, Longman, London. 335 p.

FERREIRA, S.A.N.; CLEMENT, C.R.; RANZANI, G. 1980. Contribuição para o conhecimento do sistema radicular da pupunheira (Bactris gasipaes H.B.K. = Guilielma gasipaes (H.B.K.) Bailey). I. Solo Latossolo Amarelo, textura média. Acta Amazonica 10(2): 245-249.

HARTLEY, C.W.S. 1977. The Oil Palm (Elaeis guineensis Jacq.), 2nd Ed. Tropical Agriculture Series, Longman, London. 806p.

JANOS, D.P. 1977. Vesicular-arbuscular mycorthizae affect the growth of Bactris gasipaes. Principes 21(1): 12-18.

MARSH, B.B. 1971. Measurement of length in random arrangements of lines. J. Appl. Ecol. 8: 265-267.

MARTEL, J.H.I,; CLEMENT, C.R. 1986/87. Comparação da área foliar de três acessos de pupunha (Bactris gasipaes H.B.K., Palmae) oriundos de três populações distintas da Amazônia Ocidental. Acta Amazonica 16/ 17: 13-18.
MORA URPI, J.; CLEMENT, C.R. 1988. Races and populations of peach palm found in the Amazon basin, pp. 78-94. IN: C.R. Clement and L. Coradin (eds.) Final Report (revised): Peach palm (Bactris gasipaes H.B.K.) germplasm bank. US-AID project report, Manaus, AM, Brazil.

PANDALAI, K.M. 1960. The root habit of the coconut palm. Coconut Bul. 14: 150-162.

PURVIS, C. 1956. The root system of the oil palm: its distribution, morphology and anatomy. J. West African Inst. Oil Palm Research 1(4): 60-82.

RIBEIRO, M. de N.G. 1976. Aspectos climatológicos de Manaus. Acta Amazonia 6(2): 229-233.

RIVERA C., I.P.; TRUJILLO A., F.E. 1981. Anatomia y Morfologia de la Raiz del Chontaduro (Bactris gasipaes H.B.K.). Tese, Universidad Nacional de Colombia, Facultad de Ciencias Agropecuarias, Palmira. 123p.

RUER, P. 1967a. Répartition en surface du système radiculaire du palier a huile. Oléagineux 22(8-9): 535-537.

RUER, P. 1967b. Morphologie et anatomie du système radiculaire du palmier a huile. Oléagineux 22(10): 595-599.

SCHUURMAN, J.J.; GOEDEWAAGEN, M.A.J. 1965. Methods for the Examination of Root Systems and Roots, Vada, Wageningen. 86p.

SOKAL, R.R.; ROHLF, F.J. 1981. Biometry, 2nd Ed. W.H. Freeman, New York. 859 p.

TAILLIEZ, B. 1971. Le système racinaire du palmier a huile sur la plantation de San Alberto (Colombie), Oléagineux 26(7): 435-447.

VANDERMEER, J. 1977. Observations on the root system of the pejibaye palm (Bactris gasipaes H.B.K.) in Costa Rica. Turrialba 27(3): 239-242. 